\title{
Human hydatidosis: an under discussed occupational zoonosis in India
}

\author{
B. B. SINGH ${ }^{1 *}$, G. SINGH ${ }^{2}$, R. SHARMA ${ }^{1}$, J. K. SHARMA ${ }^{1}$, R. S. AULAKH ${ }^{1}$, J. P. S. GILL ${ }^{1}$ \\ ${ }^{1}$ School of Public Health \& Zoonoses, Guru Angad Dev Veterinary \& Animal Sciences University, Ludhiana, Punjab \\ (INDIA), E-mail: balbirpau@rediffmail.com ${ }^{2}$ Civil Medical Hospital, Ludhiana, Punjab (INDIA)
}

\begin{abstract}
Summary
Human hydatidosis is an important public health issue in India and many other developing countries. There is lack of data related to occurrence of this disease in certain risk groups. The present study was therefore designed to assess the seroprevalence of human hydatidosis among occupational risk groups in Punjab (India). One hundred and forty nine human serum samples from dog handlers, veterinarians/ para veterinarians, dairy farmers, patients with liver disorders, HIV positives and control group (visiting hospital for other problems) were collected and analyzed using a commercially available enzyme linked immunosorbent assay (ELISA). The results revealed that $23(15.43 \%)$ subjects were seropositive for human hydatidosis. High seropositivity were recorded in dog handlers (30\%), followed by the other risk group populations. Relative risk of being infected was found to be 4.80 times high in dog handlers when compared to control group population. Future studies must be planned to determine the significance of these findings and the status of human hydatidosis in India.
\end{abstract}

Keywords: seroprevalence; human hydatidosis; occupational risk groups; India

\section{Introduction}

Echinococcosis due to E. granulosus is an important public health and food safety issue in India. Humans become infected by accidentally consuming eggs of Echinococcus granulosus through contaminated food, water and soil, or through direct contact with dogs (Matoff \& Kolev, 1964; Lawson \& Gemmell, 1990). The important risk factors for human infections include having a family member with the disease (Perez-Rodriguez et al., 1995; Larrieu et al., 2002), contact with dogs (Perez-Rodriguez et al. 1995), especially those that are fed or have access to raw offal (CamposBueno et al., 2000) and open, non-piped water sources (Yamamoto et al., 1996; Carmona et al., 1998). The organs most frequently affected are the liver and / or lungs (Mottaghian et al., 1982; Karpathios et al., 1985). The size of cysts in the human body is highly variable and usually ranges between 1 and $15 \mathrm{~cm}$, but much larger cysts $(>20$ $\mathrm{cm}$ in diameter) may also occur (Ammann \& Eckert, 1996; Pawlowski, 1997; Shambesh, 1997).

In Indian scenario, the conditions for the establishment and transmission of hydatidosis in both livestock and humans are very ideal. In India, unhygienic slaughtering of food animals, free access of dogs to slaughter houses, allowing dogs to eat offal's of food animals etc. undoubtedly perpetuate the transmission cycle. Irrigation of vegetables with contaminated water and soiling of vegetables by dogs and wild carnivores at night are some other factors encountered in India and other southern parts of Asia. Increasing trends in the seroprevalence of human hydatidosis has been observed in north India (Khurana et al., 2007). Despite the strong evidence to show the endemicity of this serious zoonosis, documentation and surveillance data concerning to the prevalence and risk factors associated with the disease in India is largely lacking. There is an urgent need for more recent parasite data to be obtained.

\section{Material and methods}

In the present study, 149 subjects (Table 1) visiting medical hospitals and other risk groups were approached. Each subject was informed about the objectives of the study and after their consent; the subjects belonging to different occupational groups (dog handlers, veterinarians / para veterinarians, dairy farmers, patients with liver disorders, HIV positives and control group visiting hospital for other problems) were included in this study. The serum samples and epidemiological data related to each individual subject were collected. The effect of occupation, age and sex on prevalence of infection was studied. The serum samples were stored at $-20^{\circ} \mathrm{C}$ till use. 
Table 1. Seroprevalence of human hydatidosis in different occupational groups in Punjab (India)

\begin{tabular}{|c|c|c|c|c|}
\hline $\begin{array}{l}\text { S. } \\
\text { No. }\end{array}$ & $\begin{array}{c}\text { Name of occupational } \\
\text { group }\end{array}$ & $\begin{array}{c}\text { Number of samples } \\
\text { examined }\end{array}$ & $\begin{array}{c}\text { Number of samples } \\
\text { positive }\end{array}$ & $\begin{array}{c}\text { Seroprevalence } \\
(\%)\end{array}$ \\
\hline 1. & Veterinary doctors & 41 & 6 & 14.63 \\
\hline 2. & $\begin{array}{l}\text { Dairy farmer/Farm } \\
\text { labor }\end{array}$ & 47 & 7 & 14.89 \\
\hline 3. & Dog owner/handlers & 10 & 3 & 30 \\
\hline 4. & HIV positive subjects & 8 & 2 & 25 \\
\hline 5. & $\begin{array}{l}\text { Persons with liver } \\
\text { disorders }\end{array}$ & 27 & 4 & 14.81 \\
\hline \multirow[t]{2}{*}{6.} & Control group & 16 & 1 & 6.25 \\
\hline & Total & 149 & 23 & 15.43 \\
\hline
\end{tabular}

Screening of human sera for CE was conducted employing IgG-ELISA for measurement of serum antibody (Shambesh et al., 1997) for detection of hydatid cysts. RIDASCREEN Echinococcus IgG (K 7621) ELISA kits from R - Biopharm AG, Darmstadt, Germany were used to detect the seroprevalence of human hydatidosis. This test is an enzyme immunoassay for the qualitative determination of IgG antibodies against E. granulosus and E. multilocularis in human serum. Due to the absence of definitive host for E. multilocularis in this part of the country, the seropositivity if any occurring in the samples were assumed to be due to the species E. granulosus. The test was undertaken and evaluated as per the manufacturer's instructions. The optical densities were read using ELISA Reader (Multiskan Ex Primary EIA V. 2.1-0) and were analyzed. Data were analyzed using Statistical Package for Social Sciences (SPSS 2000 for windows version 11.0.1 SPSS INC, Chicago, Illinois). The relative risk viz. the probability for the occurrence of the disease in selected occupations (exposed) versus the control (unexposed) group was analyzed. The relative risk (RR) was calculated as: Relative Risk = Probability (Diseaselexposed) divided by Probability (Disease/unexposed).

\section{Results}

Out of total of 149 serum samples examined, 23 (15.43\%) were positive for human hydatidosis. Among different occupational risk groups (Fig. 1), high seroprevalence was recorded in dog handlers ( $30 \%)$, followed by HIV positive subjects $(25 \%)$, dairy farmers/farm labour (14.89\%), persons with liver disorders $(14.81 \%)$, veterinary doctors $(14.63 \%)$ and control group $(6.25 \%)$. The relative risk of being infected was found to be 4.80, 4.00, 2.38, 2.37, 2.34 times high in dog handlers, HIV positive subjects, dairy farmers/farm labour, persons with liver disorders, and veterinary doctors respectively when compared with control group population. The seroprevalence was positively correlated with increase in age $(\mathrm{r}=+0.78)$ viz. highest in persons of more than 60 years of age and no subject was found positive in persons less than 20 years old (Fig. 2). The seroprevalence was found to be non-significantly high viz. $15.59 \%(17 / 109)$ in male when compared with female subjects where low seroprevalence of $15.0 \%(6 / 40)$ was recorded (Table 2).

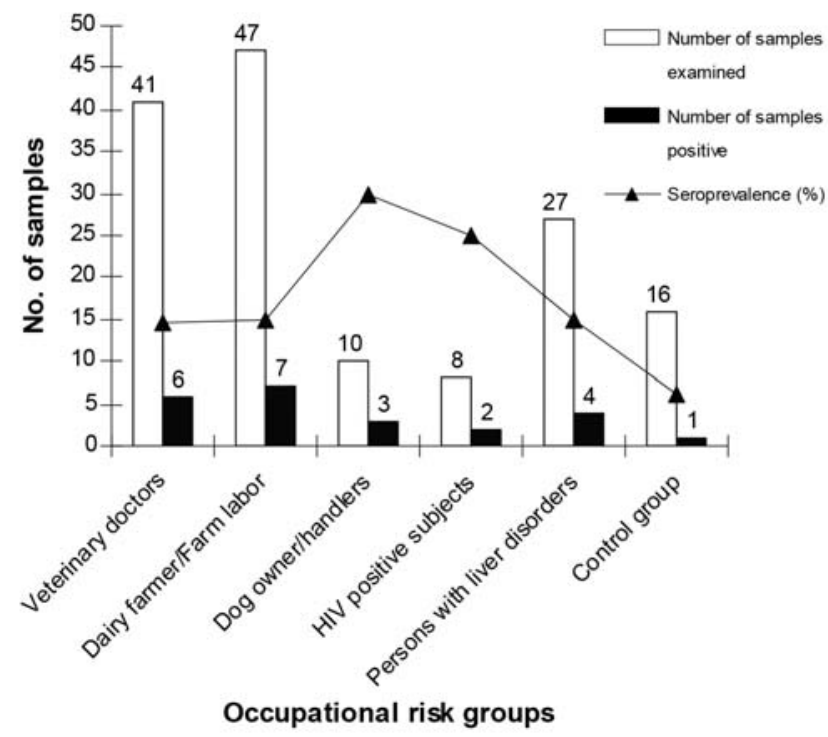




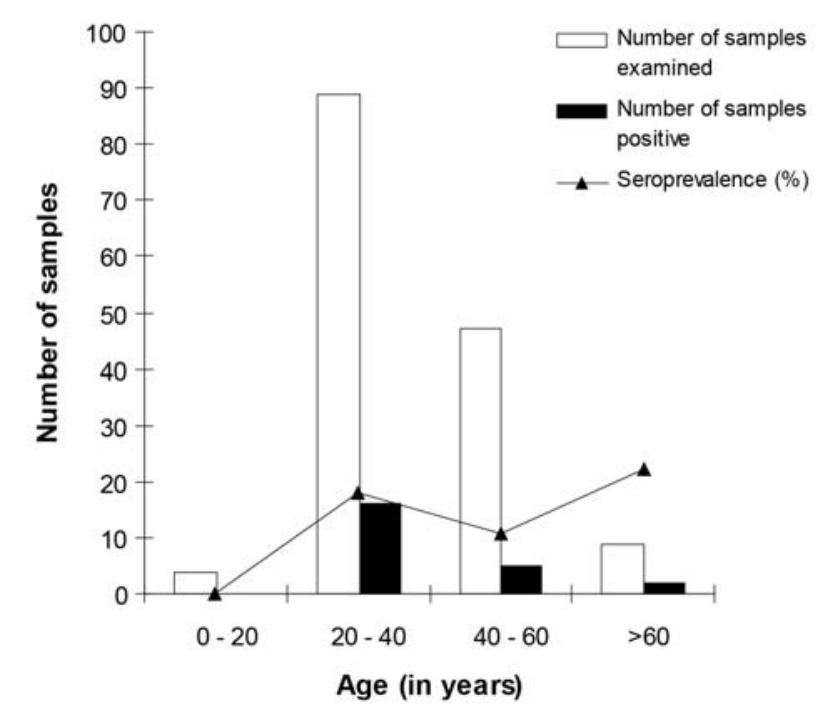

Fig. 2. Seroprevalence of human hydatidosis among different age groups in Punjab (India)

\section{Discussion}

The results are in conformity with already published reports and surveys available which reveal its occurrence in most of the states in India (Kanwar et al., 1992; Kumar and Hasan, 2008). Over 500 cases of hydatid disease requiring surgery have been sporadically reported in the human medical literature of India within the last 50 years (Traub et al., 2005). The results are in concurrence with previous study (Khurana et al., 2007) carried out at a super specialty hospital revealing significant increase $(p<0.001)$ in seropositivity during the last 5 years $(23.12 \%, 1999-2003)$ as compared with previous years $(10.97 \%, 1984-1998)$, and a similar increase $(\mathrm{p}<0.001)$ in positive Casoni's test $(33.83 \%, 1999-2003$ versus $21.38 \%, 1984-1998)$ during the same time period among suspected cases visiting this hospital. A hospital study to quantify different risk factors (Campos-Bueno et al., 2000) associated with the disease was carried out in a province marked by a high incidence of hydatidosis (Soria, Spain) and also found that odds ratios (ORs) for hydatidosis increased with the number of dogs and years of coexistence with them. The occupational distribution of patients may vary widely from country to country depending on epidemiological and socio-economic circumstances. In another study on occupational distribution of surgical cases of cystic echinococcosis in Xinjiang, People's Republic of China (1951 1990), high prevalence was recorded in farm labourer (Menghebat et al., 1993).

Cystic echinococcosis may reach medical attention in almost all ages (Utrilla et al., 1991) below 1 year of age to over 75 years old and in both sexes. Although the seroprevalence was positively correlated with increase in age ( $\mathrm{r}$ $=+0.78)$, the decrease in seroprevalence was observed in the age group of $40-60$ years. This variation might have resulted due to mode of selection and small number of patients examined in the present study. Previous studies also indicate highest numbers of $\mathrm{CE}$ cases in older age groups (Craig, 1997). In series of surgical patients, the frequency of interventions declines in older age groups, but it increases with age when populations are screened by ultrasound (Craig, 1997). However, in a Chinese series of 15289 surgical cases, $49 \%$ were in males and $51 \%$ in females (Menghebat et al., 1993). In both sexes, case numbers reached a peak between 6 and 15 years and then decreased with successive age.

The IgG-ELISA is one of the most sensitive tests presently available (WHO \& OIE, 2001) serological tests. Massscreening programmes for human $\mathrm{CE}$ have been conducted using serological tests in a number of endemic countries including Argentina, China, Israel, Kenya, Tunisia, Uruguay and others (WHO \& OIE, 2001).

\section{Conclusions}

This is a preliminary study indicating high seroprevalence among occupational risk groups in north India. Improved personnel hygiene and related public health measures must be practiced among occupational risk groups. Future studies should be planned using both serological and radiological techniques so as to know the exact prevalence of infection in the country.

Table 2. Sex wise seroprevalence of human hydatidosis

\begin{tabular}{cccc}
\hline Sex of the patient & $\begin{array}{c}\text { Number of samples } \\
\text { examined }\end{array}$ & $\begin{array}{c}\text { Number of samples } \\
\text { positive }\end{array}$ & Seroprevalence (\%) \\
\hline Male & 109 & 17 & 15.59 \\
Female & 40 & 6 & 15.0 \\
Total & 149 & 23 & 15.43 \\
\hline
\end{tabular}




\section{Conflict of interest statement}

No financial or personal relationships between the authors and other people or organizations have inappropriately influenced (bias) this work.

\section{Acknowledgement}

This study was financially supported by the School of Public Health \& Zoonoses, Guru Angad Dev Veterinary \& Animal Sciences University, Ludhiana, Punjab (India).

\section{References}

Amman, R. W., EcKert, J. (1996): Cestodes. Echinococcus. In: WeInstock J. V. (Eds) Parasitic diseases of the liver and intestines. Gastroenterology Clinical North America, pp. $655-689$

Campos-Bueno, A., López-Abente, G., S-Cercadillo, A. M. A. (2000): Risk Factors for Echinococcus granulosus infection: a case-control study. Am. J. Trop. Med. Hyg., 62(3): $329-334$

Carmona, C., Perdomo, R., Carbo, A. (1998): Risk factors associated with human cystic echinococcosis in Florida, Uruguay: results of mass screening study using ultrasound and serology. Am. J. Trop. Med. Hyg., 58: $599-$ 605

CRAIG, P. S. (1997): Immunodiagnosis of Echinococcus granulosus and a comparison of tech-niques for diagnosis of canine echinococcosis, In: ANDERSEN F. L., OUHELLI, H., KaCHANI, M. (Eds) Compendium on cystic echinococcosis in Africa and Middle Eastern Countries with Special Reference to Morocco 1997: Brigham Young University Print Services Provo, Utah, pp. $85-118$

KANWAR, J. R., KAUSHIK, S. P., SAWHNEY, I. M., KAMBOJ, M. S., Mehta, S. K., VinayaK, V. K. (1992): Specific antibodies in serum of patients with hydatidosis recognised by immunoblotting. J. Med. Microbiol., 36(1): $46-51$. DOI: $10.109 / 00222615-36-1-46$

Karpathios, T., Fretzayas, A., Nicolaidou, P. (1985): Statistical aspects of hydatid disease in Greek adults. Am. J. Trop. Med. Hyg., 34: $124-128$.

KhurAna, S., DAS, A., Malla, N. (2007): Increasing trends in seroprevalence of human hydatidosis in North India: a hospital-based study. Trop. Doct., 37(2): 100 - 102 KUMAR, S., HASAN, R. (2008): Recurrent cardiac hydatidosis in a child presenting as acute stroke. Indian J. Thorac. Cardiovasc. Surg., 24(1): 24 - 27. DOI: 10.1007/s 12055-008-007-3

larrieu, E., Costa, M. T., Cantoni, G., Alvarez, R., CAVAgION, L., LABANCHI, J. L. (2001): Ovine Echinococcus granulosus transmission dynamics in the province of Rio Negro, Argentina, 1980 - 1999. Vet. Parasitol., 98: 263 - 272. DOI: 10.1016/S0304-4017(01)00442-3
Lawson, J. R., Gemmell, M. A. (1990): Transmission of taeniid tapeworm eggs via blowflies to intermediate hosts. Parasitology, 100(1): 143 - 146. DOI: 10.1017/S00311820 00060224

MATOFF, K., Kolev, G. (1964): The role of the hairs, muzzle and paws of echinococcic dogs in the epidemiology of echinococcosis. Z. Tropenmed. Parasitol., 111: 452 - 460 Menghebat, L., Jiang, L., Chai, J. A. (1993): A retrospective survey for surgical cases of cystic echinococcosis in the Xinjiang Uygur Autonomous Region, PRC (1951 90). In: Anderson, F. L., CHAI, J., LiU, F. (Eds) Compendium on cystic echinococcosis with special reference to the Xinjiang Ugur Autonomous Region, the People's Republic of China. Brigham Young University Print Services Provo, Utah, pp. $135-145$.

MotTaghian, H., Mahmoudi, S., Vaez-ZadeH, K. (1982): A ten-year survey of hydatid disease (Echinococcus granulosus) in children. Prog. Pediatr. Surg., 15: $95-$ 112

PAWLOWSKI, Z. S. (1997): Critical points in the clinical management of cystic echinococcosis: a revised review. In: Andersen, F. L., Ouhelli, H., Kachani, M. (Eds) Compendium on cystic echinococcosis in Africa and Middle Eastern Countries with special reference to Morocco. Brigham Young University Print Services Provo, Utah, pp. $119-135$

Perez-Rodriguez, E., Bollo, E., Navio, P. (1995): An epidemiological study on the relations of patients with hydatid disease. A high-risk population? Rev. Clin. Esp., 195: $138-140$

SHAMBESH, M. K. A. (1997): Human cystic echinococcosis in North Africa (excluding Morocco). In: ANDERSEN, F. L., OuHelli, H., KaCHANI, M. (Eds) Compendium on cystic echinococcosis in Africa and Middle Eastern Countries with special reference to Morocco. Brigham Young University Print Services Provo, Utah, pp. 223 - 244

Shambesh, M. K., Craig, P. S., Ibrahem, M. M., Gusbi, A. M., ECHTUISH, E. F. (1997): A high prevalence of cystic hydatid disease in North Africa. Ann. Trop. Med. Parasitol., 91: $957-959$

Traub, R. J., Robertson, D., Irwin, P., Mencke, N., THOMPSON, R. C. A. (2005): Canine gastrointestinal parasitic zoonoses in India. Trends Parasitol., 21: 42 - 48. DOI: 10.1016/j.pt.2004.10.011

Utrilla, J. G., Eyre, F. P., Muguerza, R., Alami, H., Bueno, J. (1991): Hidatidosis en la infancia. Arch. Int. Hidatid., 30: $721-730$

WHO and OIE (2001): WHO/OIE Manual on Echinococcosis in Humans and Animals: a Public Health Problem of Global Concern, Paris, France

YAmamoto, N., OHMiYA, Y., Kishi, R., MiYAKe, H. (1996): Risk factors in serologically diagnosed echinococcosis - a case control study in the Nemuro region of Hokkaido Prefecture. Jpn. J. Public. Health, 43: 446 - 456 